\title{
Gastrointestinal Endoscopy and Coronavirus Disease-2019 Pandemic
}

\author{
Darmadi Darmadi * ${ }^{1 *}$, Cennikon Pakpahan ${ }^{2}$ (D) , Riska Habriel Ruslie ${ }^{3}$ (D) \\ ${ }^{1}$ Department of Internal Medicine, Faculty of Medicine, Universitas Sumatera Utara, Medan, Indonesia; ${ }^{2}$ Department of \\ Biomedical Sciences, Faculty of Medicine, Universitas Airlangga, Surabaya, Indonesia; ${ }^{3}$ Department of Child Health, Faculty of \\ Medicine, Universitas Prima Indonesia, Medan, Indonesia
}

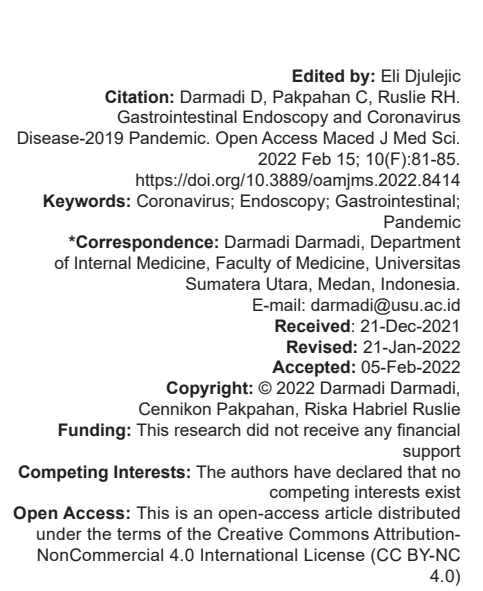

\section{Abstract}

Coronavirus disease-2019 (COVID-19) is a disease caused by severe acute respiratory syndrome-Coronavirus-2 (SARS-CoV-2). It has become a pandemic since March 11, 2020. It carries a significant burden and hampers gastrointestinal endoscopy practice. Since SARS-CoV-2 receptors are found in the gastrointestinal tract, COVID-19 also manifests as gastrointestinal symptoms. The viable virus is also detected in stool, carrying a high risk of transmission. Therefore, gastrointestinal endoscopy practice needs to be changed to prevent spreading from patients and medical personnel. All patients should be screened for the possibility of infection. Triage is done to determine the urgency of cases. Elective cases are postponed while semi-urgent and urgent cases are treated accordingly. A level 2 personal protective equipment (PPE) should be used for negative/suspected COVID-19 and a level 3 PPE is used for the confirmed case. Endoscopy unit should have negative-pressure room or proper ventilation, separated unit between negative/suspected and confirmed cases, exclusive equipment for COVID-19 case, and proper disinfection of equipment and room. Medical personnel must be screened regularly and positive information regarding gastrointestinal endoscopy practice should be spread to patients.

\section{Introduction}

Coronavirus disease-2019 (COVID-19) is a disease caused by SevereAcute Respiratory SyndromeCoronavirus-2 (SARS-CoV-2) [1], [2]. SARS-CoV-2 is a novel coronavirus identified in December 2019. It is an enveloped-single-stranded ribonucleic acid (RNA) virus from the Nidoviridales order and Coronaviridae family. The members of this family have very large genomes with many non-structural genes, making extensive frameshifting is available. Previously, other members of this family had caused the epidemic, namely severe acute respiratory syndrome in China in 2002-2004 and the Middle East respiratory syndrome in 2012-2020 in the Middle East. SARS-CoV-2 is a zoonotic virus, marked by its close relation (96\%) to bat coronavirus. The mode of transmission is mainly via inhalation of respiratory droplets and contact of respiratory droplets with oral, nasal, and eye mucous membranes. Fecal-oral transmission is suggested since viable SARS-CoV-2 can be found in the stool of patients [2], [3], [4], [5].

COVID-19 first emerges in Wuhan, China in December 2019 and spread globally [2], [6], [7], [8].
The World Health Organization declared COVID-19 as a pandemic on March 11, 2020 [3], [4]. The presence of pandemics has hardly hampered not only the socioeconomic aspect but also other healthcare programs. Particularly, programs for human immunodeficiency virus, tuberculosis, and malaria have decreased as much as $85 \%, 78 \%$, and $73 \%$, respectively. The pandemic also leads to an increased maternal death rate as high as $60 \%$ and children to death rate as high as $41 \%$ due to decreased maternal and child health services [3]. As of December 3, 2021, there are 263,563,622 confirmed COVID-19 cases globally, with 5,232,562 deaths. Most cases are from the Americas, followed by Europe and South-East Asia. The United States of America is at the top of the confirmed case toll [9].

The rate of gastrointestinal procedures decreases significantly during this pandemic [5], [10]. This phenomenon causes poorer outcomes in corresponding patients [5], [6]. For example, colorectal cancer screening in the US declined by $84.5 \%$ and in the UK by $72 \%$ [9]. We aimed to describe the impact of COVID-19 on the gastrointestinal system and gastrointestinal endoscopy practice. 


\section{Pathogenesis of Gastrointestinal Manifestations in COVID-19}

SARS-CoV-2 requires an angiotensinconverting enzyme 2 (ACE2) to enter the host's cell. The spike protein in the viral envelope will bind ACE2 and with the help of transmembrane serine protease-2 (TMPRSS-2) viral entry is made possible. Besides the respiratory tract, ACE2 and TMPRSS-2 are also abundant in the gastrointestinal tract, allowing SARSCoV-2 to affect the gastrointestinal system. The distribution covers the esophagus, gastric, duodenal, ileum, colon, and rectal epithelial cells. The expression is higher in patients with inflammatory bowel disease [4], [5], [11], [12]. After binding with ACE2, the virus will fuse with the host cell. The RNA from the virus integrates into the host cell's deoxyribonucleic acid and viral protein synthesis starts. New viruses will be assembled and released into corresponding organ systems, for example, respiratory or digestive tract, leaving damage and death to the host cell. The newly-formed viruses will invade other cells and cause further symptoms [13]. The viral RNA may be detected in the patient's stool until 33-47 days after the first onset of disease [4]. The invasion process causes inflammation, damage in the mucosa, and triggers diarrhea [14], [15]. Furthermore, inflammatory response causes microorganism imbalance in the gastrointestinal tract and compromised the digestive system's function even more [13], [16]. The effect of the gut-lung axis is also suspected to play important role in the interaction between respiratory and gastrointestinal manifestations through the common mucosal immune system [16].

\section{Clinical Manifestations of COVID-19}

The incubation period of COVID-19 ranges from 1 to 14 days with a mean of 5 days [2], [17]. Older people and males tend to have a higher risk for COVID-19 [3], [5]. The common symptoms of COVID-19 are fever, cough, and shortness of breath but gastrointestinal symptoms are also identified lately. The gastrointestinal symptoms reported are abdominal pain, nausea, vomiting, and diarrhea. The isolated gastrointestinal symptom is reported in $4 \%$ of patients while $29 \%$ is accompanied by respiratory symptoms [2], [3], [4], [5], [10]. Another study reported that $11.4 \%$ of COVID-19 patients had at least one gastrointestinal symptom. Approximately $22.97 \%$ of them presented with severe or critical disease [18]. Even though gastrointestinal symptoms are usually mild, diarrhea may end with severe dehydration and electrolyte disturbances [5]. The presence of diarrhea together with persistent symptoms of longer than
12 days is associated with unfavorable outcomes [19]. The case of acute abdomen is rarely reported including acute pancreatitis. Another gastrointestinal emergency is gastrointestinal bleeding [5].

\section{The Impact of COVID-19 on Gastrointestinal Endoscopy Practice}

Pandemic hardly affects gastrointestinal endoscopy practice. A significant decrease was observed. Literature reported that the decrease reaches $85 \%$. Another study reported a rate of decrease of more than $50 \%$. In Indonesia, the decreasing rate was $56.5 \%$. However, several gastrointestinal cases, particularly urgent and semi-urgent, need endoscopy as the management such as upper and lower gastrointestinal bleeding [5], [6], [10], [20]. Upper gastrointestinal endoscopy including retrograde cholangiopancreatography, endoscopy ultrasound, and transnasal endoscopy is categorized as aerosolgenerating procedures thus the risk of COVID-19 transmission is high [1], [5], [6], [20]. On the other hand, physical distancing is not possible to be applied during the procedure [1], [6], [11], [21]. In addition, the viable virus still can be detected in stool even after its absence in the respiratory tract specimens adding to a higher chance of transmission [1], [4], [5], [6], [10], [20]. Both patient and medical personnel safety are at risk [20]. To overcome the situation, health-care centers need to rearrange the procedures in their facilities to ensure essential management and minimize transmission [1], [5]. Most centers have utilized standard personal protective equipment (PPE); however, the rate of infection among medical personnel is still reported in $30.7 \%$ of centers [6]. Another literature reported a lower rate of 9-12\% [10]. In China, 3.8\% of medical personnel contracted COVID-19 with $14.8 \%$ of them suffering from severe conditions [3]. Some issues have disruptive effects on endoscopy practice such as shortage of PPE, lack of testing kits, reduced patient volume, workforce furloughs, and governmental rules [11]. Patients' uncertainty for contracting COVID-19 from visiting the medical facility is another important issue to overcome [5], [11].

\section{Recommendations for Gastrointestinal Endoscopy Practice during COVID-19 Pandemic}

The strict health protocol implementation is important to prevent the disease from spreading from gastrointestinal endoscopy. Physical distance should 
be kept as good as possible. Utilization of level 2 PPE is obliged during those procedures for patients with undetermined COVID-19 status. For COVID-19 negative cases, level 1 PPE is sufficient [5]. A study involving 163 endoscopists globally showed that most of them had implied the recommendations. Unfortunately, follow-up after the procedure is lacking and limits the ability to evaluate the effectiveness of the applied recommendations [6].

The Asian Pacific Society for Digestive Endoscopy (APSDE) suggests triaging and assessing the risk of COVID-19 before endoscopy. Important data which should be gathered are fever, travel history to areas with high COVID-19 transmission rate, occupational exposure to COVID-19 such as healthcare providers, cluster, and contact. Any positive finding among all of the above data should be followed by COVID-19 testing and reviewing of indications for endoscopy. Elective endoscopy should be postponed (Table 1). Urgent endoscopy should be carried on with limitation to one endoscopist and two nurses for each session. For non-suspected and COVID-19 negative patients, level 2 PPE is mandatory while level 3 PPE is required for suspected or COVID-19 confirmed patients. Mask and gloves should be changed after each session while gown down is required when contaminated. Special areas for gown up and gown down are also necessary. The availability of PPE must be guaranteed. All personnel must receive training on infection prevention measures. If available, endoscopy procedures particularly in suspected or confirmed COVID-19 should be performed in the negativepressured room, and a separated room is provided for non-COVID-19 patients. Otherwise, adequate ventilation should be assured. After utilization, the room should be cleaned thoroughly along with all the reusable instruments [1].

Table 1: Classification of endoscopic procedure urgency [1], [17], [22], [23]

\begin{tabular}{|c|c|c|}
\hline Urgent & Semi-urgent & Elective \\
\hline $\begin{array}{l}\text { Acute gastrointestinal } \\
\text { bleeding }\end{array}$ & $\begin{array}{l}\text { Treatment for gastrointestinal } \\
\text { neoplasia }\end{array}$ & $\begin{array}{l}\text { Routine diagnostic } \\
\text { endoscopy }\end{array}$ \\
\hline $\begin{array}{l}\text { Management of } \\
\text { perforations and leakage }\end{array}$ & $\begin{array}{l}\text { Case of highly suspicious } \\
\text { cancer }\end{array}$ & $\begin{array}{l}\text { Routine follow-up } \\
\text { endoscopy }\end{array}$ \\
\hline Biliary sepsis & Occult gastrointestinal bleeding & $\begin{array}{l}\text { Treatment for } \\
\text { non-malignancy }\end{array}$ \\
\hline Foreign body & $\begin{array}{l}\text { ERCP for hepatobiliary } \\
\text { pancreatic cancers }\end{array}$ & $\begin{array}{l}\text { ERCP for asymptomatic } \\
\text { stones }\end{array}$ \\
\hline $\begin{array}{l}\text { Gastrointestinal obstruction } \\
\text { requiring stenting } \\
\text { Access to urgent feeding }\end{array}$ & & $\begin{array}{l}\text { EUS for diagnosis of } \\
\text { benign condition }\end{array}$ \\
\hline
\end{tabular}

The Indonesian Society for Digestive Endoscopy releases the recommendation which is in line with APSDE. Defining patient's urgency is emphasized, followed by triage, endoscopy room standards with negative pressure, PPE, and disinfection of equipment with chlorine-based disinfectant. Patients with positive screening results will be asked to delay endoscopy for at least 14 days for elective cases. However, the emergency condition should undergo the procedure despite COVID-19 status. Some cases that underwent endoscopy is hematemesis in a cirrhotic patient, hematochezia, and foreign body obstruction. For COVID-19 confirmed patients, the highest IDSE standard should be fulfilled including negativepressured room, level 3 PPE, and exclusive equipment for the COVID-19 ward. Level 2 PPE is sufficient for handling patients with negative COVID-19 and a low risk of transmission. Limit the personnel entering the endoscopy room to minimize transmission and ensure PPE efficiency. The room should be disinfected with a chlorine-based disinfectant. Medical personnel screening should also be maintained. Personnel with suspected COVID-19 will receive proper treatment in the infection unit [17], [20], [22].

The British Society of Gastroenterology advised postponing all gastrointestinal screening for healthy patients. This action is taken to contain the infection and prevent transmission from patients to medical personnel and vice versa. Resources availability including medical personnel and PPE should be maintained regularly. Limited experienced personnel is preferred with appropriate scheduling to prevent exhaustion [23], [24].

Most centers in Belgium follow the European Society of Gastrointestinal Endoscopy or Societe Francaise d'Endoscopie Digestive guidelines in performing endoscopy on patients with COVID-19. Again, patient screening is the entry point for every endoscopy procedure. Similar questions (fever, travel history, occupation, contact, and cluster) are asked for every patient. Patients will be classified into lowrisk and high-risk groups (Table 2). A level 2 PPE and a level 3 PPE are mandatory for low- and highrisk groups, respectively. Acute upper gastrointestinal bleeding is the most common sign, followed by acute obstructive cholangitis/pancreatitis and acute lower gastrointestinal bleeding. The procedure is taken place in a specific room with different entrance and exit routes and maintained ventilation and pressure. The recovery area is also separated between COVID-19 and nonCOVID-19 cases. A set of endoscopy equipment is advised to be used only for COVID-19 patients. Disinfecting is mandatory after each procedure and all personnel are required to be trained for handling COVID-19 confirmed patient. Medical personnel should also be screened regularly to avoid transmission between personnel to personnel and personnel to

Table 2: Classification of patients requiring gastrointestinal endoscopy with potential COVID-19 [5], [10]

\begin{tabular}{ll}
\hline Risk classification & Criteria \\
\hline Low risk & No symptoms \\
& No contact history with COVID-19 positive individual \\
& No travel or residence in an area with COVID-19 \\
& transmission within the last 14 days \\
& Negative testing for COVID-19 \\
& Presence of symptoms \\
High risk & Positive contact history with COVID-19 positive individual \\
& Traveled or stayed in an area with COVID-19 transmission \\
& within the last 14 days \\
\hline
\end{tabular}


patients. Telemedicine for post-procedural follow-up is advised [10], [12]

Perisetti et al. also urge every endoscopy unit to screen all patients, stratify the urgency of endoscopy, change the endoscopy room, implement a strict protocol for PPE, proper disinfection of equipment, and longdistance follow-up after the procedure. Polymerase chain reaction testing as an initial screening procedure is reported to be helpful in reducing the economic burden of both COVID-19 and gastrointestinal disease in a patient undergoing endoscopy [11]. This is also supported by Ang from Singapore. He urged the patient and medical personnel safety with patient screening as the first step. Parameters such as fever, travel, occupation, contact, and cluster need to be evaluated. Standard PPE is mandatory with additional air purification if available. Patient triage must be implemented strictly to ensure resource and personnel availability. Proper arrangement of room entrance and exit, along with separation between positive or suspected COVID-19 patients and negative ones, plays an important role in preventing transmission [21].

All other international and national societies postpone elective cases for endoscopy during this pandemic even though there are slight differences in cases classified as urgent from one society to others. Patient's screening is mandatory, including body temperature examination and a questionnaire regarding COVID-19. The utilization of level 3 PPE for confirmed COVID-19 cases is approved by most societies based on the location's resource availability and case transmission. However, the post-procedural follow-up has not been applied in most societies [22]. Information regarding the COVID-19-minimized facility has to be delivered to patients so that they will visit hospitals and follow procedures as necessary. This is important particularly for patients with urgent situations [5].

\section{Conclusion}

Gastrointestinal endoscopy practice should be maintained to ensure optimal patient management and outcome. There are several recommendations regarding gastrointestinal practice during pandemics according to societies and studies. Patient screening is the first step, followed by triage for the case's urgency. Elective cases should be postponed while semi-urgent and urgent cases are treated accordingly with level 2 PPE and level 3 PPE for suspected/negative and confirmed COVID-19, respectively. The endoscopy unit should be changed for negative pressure or adequate ventilation, the separation between suspected/negative and confirmed COVID-19, exclusive COVID-19 equipment, and proper disinfection of equipment and room. Screening of medical personnel must be done regularly. Follow-up during the procedure is advised along with positive information regarding gastrointestinal endoscopy dissemination to patients.

\section{References}

1. Chiu PW, Ng SC, Inoue H, Reddy DN, Hu EL, Cho JY, et al Practice of endoscopy during COVID-19 pandemic: Position statements of the Asian pacific society for digestive endoscopy (APSDE-COVID statements). Gut. 2020;69(6):991-6. https:// doi.org/10.1136/gutjnl-2020-321185

PMid:32241897

2. Umakanthan S. Origin, transmission, diagnosis and management of coronavirus disease 2019 (COVID-19). Postgrad Med J. 2020;96(1142):753-8. https://doi.org/10.1136/ postgradmedj-2020-138234

PMid:32563999

3. Akande OW, Akande TM. COVID-19 pandemic: A global health burden. Niger Postgrad Med J. 2020;27(3):147-55. https://doi. org/10.4103/npmj.npmj_157_20

PMid:32687112

4. Galanopoulos M, Gkeros F, Doukatas A, Karianakis G, Pontas C, Tsoukalas N, et al. COVID-19 pandemic: pathophysiology and manifestations from the gastrointestinal tract. World J Gastroenterol. 2020;26(31):4579-88. https://dx.doi. org/10.3748\%2Fwjg.v26.i31.4579

PMid:32884218

5. Hunt RH, East JE, Lanas A, Malfertheiner $P$, Satsangi J, Scarpignato C, et al. COVID-19 and gastrointestinal disease: Implications for the gastroenterologist. Dig Dis. 2021;39(2):119-39. https://doi.org/10.1159/000512152 PMid:33040064

6. Alboraie M, Piscoya A, Tran QT, Mandelsohn RB, Butt AS, Lenz L, et al. The global impact of COVID-19 on gastrointestinal endoscopy units: An international survey of endoscopists. Arab J Gastroenterol. 2020;21(3):156-61. https://doi.org/10.1016/j. ajg.2020.08.008

PMid:32912748

7. Ruslie RH, Darmadi D, Siregar GA. Pediatric immunization practice during coronavirus disease-2019 pandemic. Open Access Maced J Med Sci. 2020;8:258-60. https://doi. org/10.3889/oamjms.2020.5125

8. Ruslie RH, Darmadi D, Siregar GA. Susceptibility of coronavirus disease-19 in pediatric population. Open Access Maced J Med Sci. 2020;8:363-5. https://doi.org/10.3889/oamjms.2020.5240

9. World Health Organization. Coronavirus Disease (COVID-19) Outbreak Situation. Geneva: World Health Organization; 2021. Available from: https://covid19.who.int [Last accessed on 2021 Dec 05].

10. Sinoquel $P$, Aerts $M$, Badaoui $A$, Bisschops $R$, Blero $D$, Demedts I, et al. BSGIE survey on COVID-19 and gastrointestinal endoscopy in Belgium: Results and recommendations. Acta Gastroenterol Belg. 2020;83(2):344-54

PMid:32603061

11. Perisetti A, Goyal H, Sharma N. Gastrointestinal endoscopy in the era of COVID-19. Front Med (Lausanne). 2020;7:587602. https://dx.doi.org/10.3389\%2Ffmed.2020.587602 PMid:33330546

12. Gralnek IM, Hassan C, Beilenhoff U, Antonelli G, Ebigbo $\mathrm{A}$, Arvanitakis $\mathrm{M}$, et al. ESGE and ESGENA position statement on gastrointestinal endoscopy and the 
COVID-19 pandemic. Endoscopy. 2020;52(6):483-90. https:// doi.org/10.1055/a-1155-6229

PMid:32303090

13. Lazaridis C, Vlachogiannis NI, Bakogiannis C, Spyridopoulos I, Stamatelopoulos K, Kanakakis I, et al. Involvement of cardiovascular system as the critical point in coronavirus disease 2019 (COVID-19) prognosis and recovery. Hellenic J Cardiol. 2020;61(6):381-95. https://doi.org/10.1016/j.hjc.2020.05.004 PMid:32534109

14. Ge H, Wang X, Yuan X, Xiao G, Wang C, Deng T, et al. The epidemiology and clinical information about COVID-19. Eur J Clin Microbiol Infect Dis. 2020;39(6):1011-9. https://dx.doi. org/10.1007\%2Fs10096-020-03874-Z

PMid:32291542

15. Satsangi J, Silverberg MS, Vermeire S, Colombel J. The Montreal classification of inflammatory bowel disease: Controversies, consensus, and implications. Gut. 2006;55(6):749-53. https:// dx.doi.org/10.1136\%2Fgut.2005.082909

PMid:16698746

16. Geng Y, Wei Z, Qian H, Huang J, Lodato R, Castriotta RJ. Pathophysiological characteristics and therapeutic approaches for pulmonary injury and cardiovascular complications of coronavirus disease 2019. Cardiovasc Pathol. 2020;47:107228. https://doi.org/10.1016/j.carpath.2020.107228

PMid:32375085

17. The Indonesian Society for Digestive Endoscopy. Clinical and Procedural Guidelines for the Gastrointestinal Endoscopy Unit during the COVID-19 Pandemic. Available from: https://pbpegi. $\mathrm{com} /$ language/en/clinical-and-procedural-guidelines-for-thegastrointestinal-endoscopy-unit-during-the-covid-19-pandemic [Last accessed on $2021 \mathrm{Dec}$ 05].

18. Jin X, Lian J, Hu J, Gao J, Zheng L, Zhang X, et al. Epidemiological, clinical and virological characteristics of
74 cases of coronavirus-infected disease 2019 (COVID-19) with gastrointestinal symptoms. Gut. 2020;69(6):1002-9. https://doi. org/10.1136/gutjnl-2020-320926

PMid:32213556

19. Hegazy MA, Lithy RM, Abdel-Hamid HM, Wahba M, Ashoush OA, Hegazy MT, et al. COVID-19 disease outcomes: Does gastrointestinal burden play a role? Clin Exp Gastroenterol. 2021;14:199-207. https://dx.doi.org/10.2147\%2FCEG.S297428 PMid:34079323

20. Pribadi RR, UtariAP, Muzellina VN, Nursyirwan AS, Maulahela H, Renaldi K, et al. Clinical practice of gastrointestinal endoscopy in COVID-19 patients: An experience from Indonesia. Clin Endosc. 2021;2021:88. https://doi.org/10.5946/ce.2021.088 PMid:34280966

21. Ang TL. Gastrointestinal endoscopy during COVID-19 pandemic. J Gastroenterol Hepatol. 2020;35(5):701-2. https:// doi.org/10.1111/jgh.15048

PMid:32216110

22. Maulahela H, Syam AF, Renaldi K, Bestari MB, Soetikno R, Abdullah $\mathrm{M}$, et al. A clinical and procedural guideline for gastrointestinal endoscopy units during COVID-19 pandemic era. Acta Med Indones. 2020;52(4):431-5.

PMid:33377889

23. British Society of Gastroenterology. Endoscopy Activity and COVID-19: BSG and JAG Guideline. Available from: https://www. bsg.org.uk/covid-19-advice/endoscopy-activity-and-covid-19bsg-and-jag-guidance [Last accessed on 2021 Dec 05].

24. Filho EC, Castro R, Fernandes FF, Pereira G, Perazzo H. Gastrointestinal endoscopy during the COVID-19 pandemic: An updated review of guidelines and statements from international and national societies. Gastrointest Endosc. 2020;92(2):440-5. e6. https://doi.org/10.1016/j.gie.2020.03.3854

PMid:32268135 